\title{
Reduction of Acetylcholinesterase Inhibition Activity of Antiscolic Herbal Compounds by Bacilli Probiotics
}

Hao Liu ( $\sim$ feliuh@scut.edu.cn )

South China University of Technology https://orcid.org/0000-0002-8481-6263

Xiaobei Gong

South China University of Technology

Yangyang Peng

Guangdong Academy of Agricultural Sciences

Chengwu Sun

Bengbu-SCUT Research Center for Advanced Manufacturing of Biomaterials

\section{Research Article}

Keywords: antiscolic herbal compounds (AHCs), acetylcholinesterase (AchE), Bacillus, inhibition

Posted Date: February 16th, 2022

DOI: https://doi.org/10.21203/rs.3.rs-1342620/v1

License: (c) (i) This work is licensed under a Creative Commons Attribution 4.0 International License.

Read Full License 


\section{Abstract}

Antiscolic herbal compounds (AHCs) are fast-growing biopesticides but must be removed afterwards from harvested crops due to their potential toxicities towards animal acetylcholine esterase (AchE). In this work, we investigated the inhibitory effect of several typical AHCs on AchE as well as their detoxification by bacilli probiotics, another group of green agricultural additives. Results showed the AchE inhibition activity of studied AHCs follows an order of berberine $\left(\mathrm{IC}_{50}=12.16 \mu \mathrm{mol} / \mathrm{L}\right)>$ osthole $(233.21 \mu \mathrm{mol} / \mathrm{L}) \approx$ matrine $(262.41 \mu \mathrm{mol} / \mathrm{L})>>$ trigonelline (no inhibition). Molecular simulation predicted that berberine, matrine and osthole combine with AchE preferentially in the catalytic channel for acetylcholine (Trp84 and His440), but forming more stable complexes. At the $\mathrm{IC}_{50}$ dosage, the addition of Bacillus subtilis $\left(10^{6} \sim 10^{7} \mathrm{CFU} / \mathrm{mL}\right)$ or several other bacilli species detoxified osthole from $50 \%$ AchE inhibition to around $30 \%$. Slight detoxification of matrine was also observed but the toxicity of berberine was not influenced after incubated with bacilli probiotics. Conversely, the three AHCs could completely inhibited the growth of $B$. subtilis following an order of berberine $(0.15 \mathrm{mmol} / \mathrm{L})>$ Matrine $(9 \mathrm{mmol} /)>$ osthole $(1.5 \mathrm{mmol} / \mathrm{L})$. B. subtilis Ruizhen@ exhibited stronger tolerance to AHCs than other commercial strains. Among other tested species, $B$. mucilaginosus was less sensitive than $B$. subtilis while $B$. laterosporus and $P$. polymyxa were resistant to AHCs. The potential antagonistic actions between AHCs and bacilli probiotics maybe useful in removal of residual herbal toxicity with green bacterial sweeper.

\section{Introduction}

The harmful effects of synthetic pesticides on human health have caused worldwide attention in recent years. A promising solution is to develop natural compounds from antiscolic herbs as a substitute to meet the demand of sustainable agriculture (Chaudhary et al. 2017). Coptis root, sophora root, and fruit of Fructus cnidii are all traditional Chinese medicines for insect repellent (Zhang et al. 2018). Berberine extracted from coptis root is a rotenoid that strongly inhibits the mitochondrial respiratory chain of pests, resulting in respiratory disorders, paralysis and death (Li et al. 2018). Berberine also targets on water insects including aphids, thrips, beetles, spider mites, etc (Li et al. 2018). Matrine is an alkaloid isolated from saphoro root. It kills pests by paralyzing their nervous system after immediate contact and subsequently denaturalizing the albumen proteins in their bodies, which finally causes the insects to die of suffocation (Zanardi et al. 2015). Osthole is coumarin compound from Fructus cnidii which also acts on the nervous system of pests, causing non-functional contraction of the muscles and eventually dying (Yan et al. 2021). Some of these antiscolic herbal compounds (AHCs), i.e. berberine, has been commercially applied to replace synthetic organophosphorus pesticides for planting fruit trees and vegetables. However, many AHCs exhibit neurotoxicity not only towards insects but also to higher animals (Lu et al. 2014) especially when exceeding safe concentrations. Safe approaches to detoxicify AHCs are currently in urgent need.

Bacilli probiotics have already applied in cultivation of herbs as well as in the composting of herbal medicine residue (Prakash et al. 2017; Chang et al. 2020). Bacillus is one of the most representative 
families, among which, $B$. subtilis has been widely used as biofungicide for controlling pre- and postharvest herbal plant pathogens through production of antibiotics, nutrient competition and induction of systemic resistance in the host plant (Fira et al. 2018). In addition to $B$. subtilis, $B$. thuringiensis, $B$. pumilus, $B$. licheniformis and several other species have also been approved in many countries for herbal plant protection and growth stimulation in agriculture (Jurat-Fuentes et al. 2021; Gutiérrez-Mañero et al. 2010). This raises us a question that would live bacteria reduce the residual toxicity of AHCs? The potential antagonistic role played by bacilli probiotics may arise a new detoxification approach for safe use of $\mathrm{AHC}$ biopesticides. On the other hand, previous authors have reported the antimicrobial activities of AHCs against bacterial strains including Escherichia coli, Staphylococcus aureus and B. cereus (Pierpaoli et al. 2021; Sun et al. 2021; More et al. 2017). Investigation of anti-bacilli activity of AHCs is also important for fully understanding the potential antagonistic effects between the two kinds of agricultural additives when used simultaneously or within a short service interval. However, to the best knowledge of us, the interactions between specific AHCs and live bacilli probiotics have not been well studied. This work focused on this topic and may help to optimize the application of AHCs and probiotics in for sustainable agriculture.

\section{Materials And Methods}

\section{Chemicals}

All chemicals were purchased from Macklin Chemical Reagent Co. Ltd. (Shanghai, China). The basic information of $4 \mathrm{AHCs}$, matrine, berberine, osthole and trigonelline were obtained from the supplier as summarized in Table 1. Trigonelline is a major soluble alkaloid extracted from Trigonella foenum graecum seed, a Chinese traditional antiscolic herbal medicine.

\section{Acetylcholinesterase (AchE) Inhibition Test}

The AchE inhibition by AHCs and bacillus were quantitatively determined using a HPER-40T pesticide residue detector and the matching assay kit (HPER Scientific Instrument Co., Ltd., Guangzhou, China). The following reagents were pipetted in a 4-mL cuvette: $0.14 \mathrm{~mL}$ of phosphate buffer $(20 \mathrm{mM}, \mathrm{pH}$ 7.6), $0.05 \mathrm{~mL}$ of acetylthiocholine iodide $(5 \mathrm{mM})$, and $0.01 \mathrm{~mL}$ of AHC solution (water as reference). After incubation at $38^{\circ} \mathrm{C}$ for $10 \mathrm{~min}$, the reaction was stopped with $1.8 \mathrm{~mL}$ of 5,5'-dithiobis-2-nitrobenzoic acid (DTNB)-phosphate ethanol reagent supplied by HPER. The color change at $412 \mathrm{~nm}$ was recorded immediately from which the concentration to inhibit $50 \%$ of $A c h E\left(\mathrm{IC}_{50}\right)$ was reported.

\section{Molecular Simulation}

An AchE model, 1UT6, was obtained from the Protein Data Bank database (http://www.rcsb.org) for simulating the binding of AHCs. All the 3D structural files of AHCs were obtained from ChemSpider. In the software Autodock 4.2, the PDB files of AchE and AHCs were rewritten to be PDBQT format, following with docking procedures based on Lamarckian Genetic Algorithm. The gridbox parameters were set as below: number of points in $\mathrm{x}, \mathrm{y}$ and $\mathrm{z}$ dimension was 126,126 and 126 respectively; spacing $=0.5 \AA$; 
center $x=4.85, y=64.409, z=56.065$. The number of GA runs was 200 and the population size was 400 . The output data were redrawn in UCSF Chimera software. The amino acids interacted with AHC ligands were analyzed using the LigPlus tools.

\section{Bacterial Strains and Culture Conditions}

B. subtilis Ruizhen@ biofungicide was purchased from Beijing Coway BioWorks Biotech Co., Ltd. (Beijing, China) in the form of dried powder. The active endospores were $1 \times 10^{10} \mathrm{CFU} / \mathrm{g}$ as denoted by the supplier and the filler in powder products was soluble and non-nutrient. Colonies of live cells were obtained after spreading $10 \mu \mathrm{L}$ diluent ( $10^{8}$ dilution) of RuiZhen@ biofungicide on plates of Chromogenic Bacillus Cereus Agar (CBCA, Huankai, Guangdong, China) and incubating at $30^{\circ} \mathrm{C}$ for $24 \mathrm{~h}$. A single colony was inoculated in nutrient broth (peptone $10 \mathrm{~g} / \mathrm{L}$, beef extract $3 \mathrm{~g} / \mathrm{L}, \mathrm{NaCl} 5 \mathrm{~g} / \mathrm{L}, \mathrm{pH} 7.3 \pm 0.2$ ) and cultivated at $30^{\circ} \mathrm{C}, 120 \mathrm{rpm}$ for $2 \mathrm{~h}$. Then the broth was centrifuged at $4^{\circ} \mathrm{C}, 10000 \mathrm{rpm}$ for $5 \mathrm{~min}$. The precipitate was washed with sterile saline for 3 times and finally diluted to a suspension containing living cells of $1 \times 10^{7}$ $\mathrm{CFU} / \mathrm{g}$. All the plates with isolated colonies were preserved only for experiment and were heat sterilized after this research.

Other two commercial B. subtilis products were purchased from BION Tech Inc. (BTI, Taiwan, China) and Beihai Qiangxing Biotech Co., Ltd. (Guangxi, China), respectively, denoted as Y1336 and BHQX according to the suppliers. Bacillus mucilaginosus, Brevibacillus laterosporus and Paenibacillus polymyxa were obtained from Guangdong Microbial Culture Collection Center (GDMCC).

\section{Bacterial activity test}

All cell suspensions of bacteria were properly diluted, inoculated $(20 \mu \mathrm{L})$ and spread onto CBCA plates. The plates were incubated at $30^{\circ} \mathrm{C}$ for $24 \mathrm{~h}$. The number of Bacillus colonies with blue-green color was counted and reported into $\mathrm{CFU} / \mathrm{mL}$.

\section{Results And Discussion}

\section{AchE Inhibition by AHCs}

The AchE inhibitory effect of the tested 4 AHCs was determined as shown in Figure 1 from which the respective $I_{50}$ values were obtained as summarized in Table 2. Berberine hemisulfate exhibited the strongest inhibition with an $\mathrm{IC}_{50}$ value $(12.16 \mu \mathrm{mol} / \mathrm{L})$ an order of magnitude lower than that of matrine $(262.41 \mu \mathrm{mol} / \mathrm{L})$ or osthole $(233.21 \mu \mathrm{mol} / \mathrm{L})$. No toxicity for trigonelline chloride was detected in the tested range.

It was worth to mention that osthole was dispersed in the form of emulsion due to it is slightly soluble in water. When testing a suspension of osthole in water instead of emulsion, at most $24 \%$ AchE activity loss was obtained at a content of $30 \mu \mathrm{mol} / \mathrm{L}$. The activity loss was maintained at about $20 \%$ within a wide range of osthole content in aqueous suspension up to $244 \mu \mathrm{mol} / \mathrm{L}$ (Figure S1). This inhibition limit 
probably corresponds to the dissolution ratio of osthole in water, and only those dissolved part nonproductively binds with AchE.

The binding of AHCs in AchE was simulated using Autodock and the results were shown in Figure 2. Berberine, matrine and osthole preferentially bound with AchE at the catalytic channel which is also anchored by the regular substrate, acetylcholine. The binding energies were $-9.11,-9.41$ and -7.99 $\mathrm{kcal} / \mathrm{mol}$, respectively (Table 2). The absolute values were much higher than that of acetylcholine (-4.75 $\mathrm{kcal} / \mathrm{mol}$ ), suggesting that the three AHCs formed more stable complex conformations with AchE than acetylcholine. Trigonelline was significantly different from them. It took up a favorite binding site away from the catalytic channel, suggesting there is no AchE inhibition effect of trigonelline. This was in accordance with the data as illustrated in Figure 1.

The amino acids interacted with AHC ligands were summarized in Table 2. Trp84, Phe330 and His440 were identical binding sites for both substrate (acetylcholine) and inhibitor (matrine, berberine or osthole). In previous papers, amino acids Trp84, Tyr130, Phe330 and Phe331 are responsible for the molecular recognition of quaternary ammonium ligands and also the catalytic anionic sites (Lee et al. 2015; Takomthong et al. 2021). Therefore, the three AHCs probably inhibit AchE through competitively occupation of the active catalytic channel. Berberine and matrine were stronger inhibitors than osthole probably due to that their higher binding energies (Table 2). Trigonelline preferably anchored the hydrophilic valley at the N-terminal of AchE, showing no competition with acetylcholine and thus no inhibition. It can be further deduced that trigonelline is probably not the active component in Ttigonella foenum graecum seed which has been considered as a kind of antiscolic herb.

\section{Detoxicification of AHCs by Bacillus}

B. subtilis Ruizhen@ was added into the AchE inhibition test system together with berberine, matrine and osthole at their respective $\mathrm{IC}_{50}$ concentration. The total live cell number of Ruizhen@ was $1 \times 10^{6} \mathrm{CFU} / \mathrm{mL}$. These bacteria at this content level did not show any impact on the AchE activity (Figure 3a). After incubation at $30^{\circ} \mathrm{C}$ for $2 \mathrm{~h}$, both berberine and matrine caused half loss of the AchE activity in presence of Ruizhen@ (Figure 3a). Interestingly, in the test of osthole incubated with Ruizhen@ at $10^{6} \mathrm{CFU} / \mathrm{mL}$ level, the AchE activity loss was decreased to $66.57 \%$. The results clearly indicate a detoxification of osthole with the addition of Ruizhen ${ }^{\circledR}$.

At a higher content of live cells, i.e. $10^{7}$ and $10^{8} \mathrm{CFU} / \mathrm{mL}$, B. subtilis Ruizhen ${ }^{\circledR}$ independently depressed AchE activity by about $15 \%$ and $22 \%$, respectively. These inhibition data were much lower than the alarming line (50\% loss) and were considered to be safe in general (Printes et al. 2004). After incubating Ruizhen ${ }^{\circledR}$ and the three AHCs at $30^{\circ} \mathrm{C}$ for $2 \mathrm{~h}$, only berberine kept the same toxicity level to AchE. The measured AchE loss by combination of Ruizhen@ and berberine was almost exact half of the value of reference. In another word, there was no detoxification effect on berberine by incubation with bacillus Ruizhen@. 
However, the toxicities of matrine and osthole as represented by AchE inhibition were obviously weakened after incubated with Ruizhen ${ }^{@}\left(10^{7}\right.$ or $\left.10^{8} \mathrm{CFU} / \mathrm{mL}\right)$. Their retained AchE activities were all above the expected half-loss line as shown in Figure 3a. The antagonistic effect suggests that Ruizhen@ is not suitable for mixed use together with biopesticides containing matrine and osthole and can somehow detoxify these two biopesticides residues.

Detoxification effects were also found when incubating AHCs with other bacilli species (Figure 3b). Such effect on osthole was more obvious than on matrine. At the $\mathrm{IC}_{50}$ dosages, the addition of Bacillus subtilis $\left(10^{7} \mathrm{CFU} / \mathrm{mL}\right)$ or several other bacilli species detoxified osthole from $50 \%$ AchE inhibition to around $30 \%$. There was still no obvious change found in the case of berberine. On the other hand, $P$. polymyxa gave stronger AchE toxicity than $B$. subtilis. Mixing these two probiotics $\left(10^{7} \mathrm{CFU} / \mathrm{mL}\right)$ with berberine $\left(\mathrm{IC}_{50}\right.$ concentration) resulted in remarkable $\mathrm{AchE}$ inhibition degree up to $67 \%$.

\section{Growth Inhibition of Bacilli by AHCs}

The antimicrobial activity of AHCs were tested with B. stibilis Ruizhen@ and the results were demonstrated in Figures 4 and 5. Separate green round colonies occurred after 24-h incubation of diluted cell suspensions of Ruizhen ${ }^{@}$ spread on CBCA plates. Numbers of colonies were decreased due to the addition of AHCs. There was a narrow tolerance range for Ruizhen@ to berberine $(0 \sim 0.012 \mathrm{mmol} / \mathrm{L})$, matrine $(0 \sim 4.2 \mathrm{mmol} / \mathrm{L})$ and osthole $(0 \sim 0.53 \mathrm{mmol} / \mathrm{L})$. Within the respective tolerant range, the loss of living cells was less than $15 \%$. Berberine, matrine and osthole completely inhibited the growth of $B$. stibilis $\left(4.2 \times 10^{7} \mathrm{CFU} / \mathrm{mL}\right)$ at a concentration of $0.43,3.37$ and $9.22 \mathrm{mmol} / \mathrm{L}$, respectively.

Compared with Ruizhen ${ }^{\circledR}$, the other two B. stibilis strains, BHQX and Y1336, showed much lower resistance to berberine, matrine and osthole. They were completely inhibited by berberine at $0.1 \mathrm{mmol} / \mathrm{L}$ and by matrine at $2.25 \mathrm{mmol} / \mathrm{L}$. Osthole was also very toxic to them, inhibited $94.4 \%$ and $82.2 \%$ of live cells at a content of $0.5 \mathrm{mmol} / \mathrm{L}$. As a comparison, no significant inhibition occurred in the test of Ruizhen ${ }^{\circledR}$. This indicates the importance of training bacterium strains to be tolerant to certain AHCs before applying them to herbal plants.

Unlike $B$. stibilis, the other three bacilli species generally showed higher tolerance when exposed to berberine, matrine and osthole, following the order: B. mucilaginosus $>$ B. laterosporus $\sim P$. polymyxa (Table 3 ). The only exception is that $B$. mucilaginosus was more sensitive to matrine and osthole than B. stibilis Ruizhen ${ }^{@}$. Among all the tested strains, B. laterosporus had the highest tolerance to AHCs. Little inhibitory effect was detected in the presence of herbal compounds within the tested concentration ranges.

Results also suggests the importance of training probiotic microbes that tolorate the anti-microbial activity of AHCs if they are used for detoxification purpose. The studied three AHCs could completely inhibited the growth of $B$. subtilis following an order of berberine $(0.15 \mathrm{mmol} / \mathrm{L})>$ Matrine $(9 \mathrm{mmol} / \mathrm{L})>$ osthole $(1.5 \mathrm{mmol} / \mathrm{L})$. In lit-erature, the potential of berberine as an antimicrobial agent against mixed 
microorganisms containing E. coli and B. subtilis has been reported by Kong et al. (2012). They found a low concentration $(20 \mu \mathrm{g} / \mathrm{mL})$ of berberine began to inhibit the growth of $E$. coli and mixed microorganisms, while promoting the growth of B. subtilis (Kong et al. 2012). Deep mechanism study revealed that berberine can inhibit not only $B$. subtilis cell growth, but also spore outgrowth, including inhibiting protein synthesis during this period (Wang et al. 2015). The presence of L-valine prevented the effect of berberine $(200 \mu \mathrm{g} / \mathrm{mL}$ ) on B.subtilis spore germination (Wang et al. 2015). Impressively, our data in Table 3 showed berberine blocked the growth of B.subtilis strains but more compatible with B.mucilaginosus, B.laterosporus and P. polymyxa. In another word, B.mucilaginosus and B.laterosporus were less sensitive to berberine $(0.1 \mathrm{mmol} / \mathrm{L})$ than $B$. subtilis strains. There might be metabolites by these two species that play a role in detoxification of berberine. The combination of $P$. polymyxa and berberine could be further explored through insecticide for developing conjugated bioinsectsides.

Antimicrobial properties of matrine are associated with glycerophospholipid metabolism and the sphingolipid metabolic signaling pathways (Huang et al. 2016). Previous authors reported matrine enhanced the pathogenicity of Beauveria brongniartii against agricultural insect pests (Wu et al. 2019). Osthole kill both Gram positive and negative bacteria by inhibiting the absorption of $\mathrm{Ca}^{2+}$, which affects the growth and spore germination of the bacteria and inhibits chitin deposition of the bacterial cell wall (Sun et al. 2021). Supplemental of soluble calcium salts in decomposition of osthole-containing herbal residues by Bacillus may help preserve the living cells.

\section{Conclusion}

The three AHCs, berberine $\left(\mathrm{IC}_{50}=12.16 \mu \mathrm{mol} / \mathrm{L}\right)$, matrine $(262.41 \mu \mathrm{mol} / \mathrm{L})$ and osthole $(233.21 \mu \mathrm{mol} / \mathrm{L})$ are all AchE inhibitors that could enter the catalytic channel of the enzyme and occupy key amino acids competing with the regular substrate. They could also completely inhibite the growth of $B$. subtilis following an order of berberine $(0.15 \mathrm{mmol} / \mathrm{L})>$ Matrine $(9 \mathrm{mmol} / \mathrm{L})>$ osthole $(1.5 \mathrm{mmol} / \mathrm{L})$. Addition of Bacillus subtilis $\left(10^{6} \sim 10^{7} \mathrm{CFU} / \mathrm{mL}\right)$ or several other Bacilli species detoxified matrine and osthole to some extent suggesting obvious antagonistic action between Bacilli and some AHCs. The toxicity of berberine was not influenced by the incubation with Bacilli probiotics. Berberine also blocked the growth of B.subtilis strains but more compatible with B.mucilaginosus, B.laterosporus and P. polymyxa. Our results may be helpful for the further combined utilization of AHCs biopesticidesand microbial probiotics.

\section{Declarations}

\section{Acknowledgement}

The Science and Technology Program of Guangzhou (No.201704020038), the Guangdong Natural Science Foundation (No.2017A030310341), the Foundation of State Key Laboratory of Pulp and Paper Engineering (No.2017QN01 and No.2017PY01), and the Fundamental Research Funds for the Central Universities (No.x2qsD2142050) are gratefully acknowledged. 


\section{References}

1. Chang F, Jia F, Lv R, Zhen L, Li Y, Wang Y (2020) Changes in structure and function of bacterial and fungal communities in open composting of Chinese herb residues. Can J Microbiol 66(3):194-205. https://doi.org/10.1139/cjm-2019-0347

2. Chaudhary S, Kanwar RK, Sehgal A, Cahill DM (2017) Progress on Azadirachta indica based biopesticides in replacing synthetic toxic pesticides. Front Plant Sci 8: 610. https://doi.org/10.3389/fpls.2017.00610

3. Fira D, Dimkić I, Berić T, Lozo J, Stanković S (2018) Biological control of plant pathogens by Bacillus species. J Biotechnol 285: 44-55. https://doi.org/10.1016/j.jbiotec.2018.07.044

4. Gutiérrez-Mañero FJ, Ramos-Solano B, Probanza A, Mehouachi J, Tadeo FR, Talon M (2010) The plant-growth-promoting rhizobacteria Bacillus pumilus and Bacillus licheniformis produce high amounts of physiologically active gibberellins. Physiol Plant 111: 206-211. https://doi.org/10.1034/j.1399-3054.2001.1110211.x

5. Huang J, Xu H (2016) Matrine: bioactivities and structural modifications. Curr Top Med Chem 16(28): 3365-3378. https://doi.org/10.2174/1568026616666160506131012

6. Jurat-Fuentes JL, Heckel DG, Ferré J (2021) Mechanisms of resistance to insecticidal proteins from Bacillus thuringiensis. Ann Rev Entomol 66: 121-140. https://doi.org/10.1146/annurev-ento-052620073348

7. Kong WJ, Xing XY, Xiao XH, Zhao YL, Wei JH, Wang JB, Yang RC, Yang MH (2012) Effect of berberine on Escherichia coli, Bacillus subtilis, and their mixtures as determined by isothermal microcalorimetry. Appl Microbiol Biot 96(2): 503-510. https://doi.org/10.1007/s00253-012-4302-y

8. Lee S, Barron MG (2015) Development of 3D-QSAR model for acetylcholinesterase inhibitors using a combination of fingerprint, molecular docking, and structure-based pharmacophore approaches. Toxicol Sci 148(1): 60-70. https://doi.org/10.1093/toxsci/kfv160.

9. Li Y, Yin YM, Wang XY, Wu H, Ge XZ (2018) Evaluation of berberine as a natural fungicide: Biodegradation and antimicrobial mechanism. J Asian Nat Prod Res 20: 148-162. https://doi.org/10.1080/10286020.2017.1329300

10. Lu ZG, Li MH, Wang JS, Wei DD, Liu QW (2014) Developmental toxicity and neurotoxicity of two matrine-type alkaloids, matrine and sophocarpine, in zebrafish (Danio rerio) embryos/larvae. Reprod Toxicol 47: 33-41. https://doi.org/10.1016/j.reprotox.2014.05.015

11. More NV, Kharat KR, Kharat AS (2017) Berberine from Argemone mexicana L exhibits broadspectrum antibacterial activity. Acta Biochim Pol 64(4): 653-660. https://doi.org/10.18388/abp.2017_1621

12. Pierpaoli E, Cirioni O, Simonetti O, Orlando F, Giacometti A, Lombardi P, Provinciali M (2021) Potential application of berberine in the treatment of Escherichia coli sepsis. Nat Prod Res 35(22):47794784. https://doi.org/10.1080/14786419.2020.1721729

13. Prakash J, Arora NK (2019) Phosphate-solubilizing Bacillus sp. enhances growth, phosphorus uptake and oil yield of Mentha arvensis L. 3 Biotech 9(4):126. https://doi.org/10.1007/s13205-019-1660-5 
14. Printes LB, Callaghan A (2004) A comparative study on the relationship between acetylcholinesterase activity and acute toxicity in Daphnia magna exposed to anticholinesterase insecticides. Environ Toxicol Chem 23(5): 1241-1247. https://doi.org/10.1897/03-202

15. Sun $\mathrm{H}$, Ansari MF, Fang B, Zhou CH (2021) Natural berberine-hybridized benzimidazoles as novel unique bactericides against Staphylococcus aureus. J Agr Food Chem 69(28): 78317840. https://doi.org/10.1021/acs.jafc.1c02545

16. Sun M, Sun M, Zhang J (2021) Osthole: an overview of its sources, biological activities, and modification development. Med Chem Res 30:1767-1794. https://doi.org/10.1007/s00044-02102775-w

17. Takomthong P, Waiwut P, Yenjai C, Sombatsri A, Reubroycharoen P, Lei L, Lai R, Chaiwiwatrakul S, Boonyarat C (2021) Multi-target actions of acridones from Atalantia monophylla towards Alzheimer's pathogenesis and their pharmacokinetic properties. Pharmaceuticals 14(9): 888. https://doi.org/10.3390/ph14090888

18. Wang S, Yu J, Suvira M, Setlow P, Li Y (2015) Uptake of and resistance to the antibiotic berberine by individual dormant, germinating and outgrowing Bacillus spores as monitored by laser tweezers Raman spectroscopy. PloS One 10(12): e0144183. https://doi.org/10.1371/journal.pone.0144183

19. Wu J, Yu X, Wang X, Tang L, Ali S (2019) Matrine enhances the pathogenicity of Beauveria brongniartii against Spodoptera litura (Lepidoptera: Noctuidae). Front Microbiol 10: 1812. https://doi.org/10.3389/fmicb.2019.01812

20. Yan S, Hu Q, Jiang Q, Chen H, Wei J, Yin M, Du X, Shen J (2021) Simple osthole/nanocarrier pesticide efficiently controls both pests and diseases fulfilling the need of green production of strawberry. ACS Appl Mater Interfaces 13(30): 36350-36360. https://doi.org/10.1021/acsami.1c09887

21. Zanardi OZ, Ribeiro LP, Ansante TF, Santos MS, Bordini GP, Yamamoto PT, Vendramim JD (2015) Bioactivity of a matrine-based biopesticide against four pest species of agricultural importance. Crop Prot 67: 160-167. https://doi.org/10.1016/j.cropro.2014.10.010

22. Zhang L, Lin M, He C, Cheng Q (2018) Development of "traditional Chinese medicine agriculture" to establish ecological agriculture with the Chinese characteristics. J Med Plants Stud 6(6): 95-99.

\section{Tables}

Table 1 AHCs used in this work 


\begin{tabular}{|ll|}
\hline Chemical name \& CAS No. & Formula, Molecular weight \& Purity \\
\hline Matrine & $\mathrm{C}_{15} \mathrm{H}_{24} \mathrm{~N}_{2} \mathrm{O}$ \\
$(\mathrm{CAS} 519-02-8)$ & $248.36 \mathrm{~g} / \mathrm{mol}$ \\
& $98 \%$ \\
\hline Berberine Hemisulfate & $\mathrm{C}_{20} \mathrm{H}_{18} \mathrm{NO}_{4} \cdot 1 / 2 \mathrm{SO}_{4}$ \\
$(\mathrm{CAS} 633-66-9)$ & $384.4 \mathrm{~g} / \mathrm{mol}$ \\
& $95 \%$ \\
\hline Osthole & $\mathrm{C}_{15} \mathrm{H}_{16} \mathrm{O}_{3}$ \\
(CAS 484-12-8) & $540.6 \mathrm{~g} / \mathrm{mol}$ \\
& $99 \%$ \\
Trigonelline chloride & $\mathrm{C}_{7} \mathrm{H}_{8} \mathrm{ClNO}_{2}$ \\
(CAS 6138-41-6) & $173.6 \mathrm{~g} / \mathrm{mol}$ \\
& $99 \%$
\end{tabular}

Table 2 Inhibitory binding of AHCs to AchE simulated with Autodock

\begin{tabular}{|c|c|c|c|c|}
\hline Ligand & $\mathrm{IC}_{50}(\mu \mathrm{mol} / \mathrm{L}) *$ & $\begin{array}{l}\text { Binding } \\
\text { energy } \\
\text { (kcal/mol) }\end{array}$ & $\begin{array}{l}\text { Inhibition } \\
\text { constant } \\
(\mu \mathrm{M})\end{array}$ & Amino acids residues at binding sites ${ }^{\star *}$ \\
\hline Acetylcholine & - & -4.75 & 331.81 & $\begin{array}{l}\text { Trp84, Gly117, Gly118, Gly119, Tyr130, } \\
\text { Glu199, Ser200, Phe288, Phe290, } \\
\text { Phe331, His440, Gly441 }\end{array}$ \\
\hline Matrine & 262.41 & -9.41 & 0.13 & $\begin{array}{l}\text { Trp84, Glu199, Phe330, Tyr334, Trp432, } \\
\text { Ile439, His440, Gly441, Tyr442 }\end{array}$ \\
\hline Berberine & 12.16 & -9.11 & 0.21 & $\begin{array}{l}\text { Gln69, Tyr70, Asp72, Trp84, Asn85, } \\
\text { Pro86, Gly118, Ser122, Gly123, Phe330, } \\
\text { Tyr334, Trp432, Met436, Ile439, His440, } \\
\text { Tyr442, }\end{array}$ \\
\hline Osthole & 233.21 & -7.99 & 1.38 & $\begin{array}{l}\text { Asp72, Ser81, Trp84, Gly117, Ser122, } \\
\text { Gly123, Leu127, Tyr130, Glu199, } \\
\text { Phe330, Tyr334, His440, }\end{array}$ \\
\hline Trigonelline & ND & -4.48 & 520.33 & $\begin{array}{l}\text { Arg468, His471, Tyr472, Pro482, } \\
\text { Asn483, Glu484, Lys491 }\end{array}$ \\
\hline
\end{tabular}

* $\mathrm{All} I \mathrm{IC}_{50}$ data were tested in triplicate; 
**The amino acids participating the hydrogen bonding were marked in bold. .

Table 3 Growth inhibition of other bacilli species

\begin{tabular}{|lllllllll|}
\hline Strain & Control & \multicolumn{3}{c}{ Matrine $(\mathrm{mmol} / \mathrm{L})$} & \multicolumn{3}{c|}{ Berberine $(\mathrm{mmol} / \mathrm{L})$} & \multicolumn{2}{c|}{ Osthole $(\mathrm{mmol} / \mathrm{L})$} \\
\cline { 3 - 9 } & & 2.25 & 5.8 & 0.025 & 0.05 & 0.1 & 0.5 & 1.0 \\
\hline B.s. Ruzen@ & 42.0 & 38.0 & 15.5 & 35.0 & 13.5 & 2.4 & 40.3 & 0.5 \\
B.s.BHQX & 44.1 & 0.0 & 0.0 & 14.4 & 0.0 & 0.0 & 2.5 & 0.0 \\
B.s.Y1336 & 24.6 & 0.0 & 0.0 & 7.5 & 2.0 & 0.0 & 4.4 & 2.1 \\
B.mucilaginosus & 36.2 & 17.3 & 17.3 & 31.6 & 33.6 & 27.8 & 18.4 & 11.6 \\
B.laterosporus & 43.4 & 43.1 & 40.5 & 44.5 & 35.1 & 37.7 & 42.0 & 39.0 \\
\hline P. polymyxa & 39.5 & 32.8 & 30.6 & 42.6 & 38.2 & 28.2 & 33.3 & 37.9 \\
\hline
\end{tabular}

Note: The unit of living cell content is million $\mathrm{CFU} / \mathrm{mL}$.

Figures 


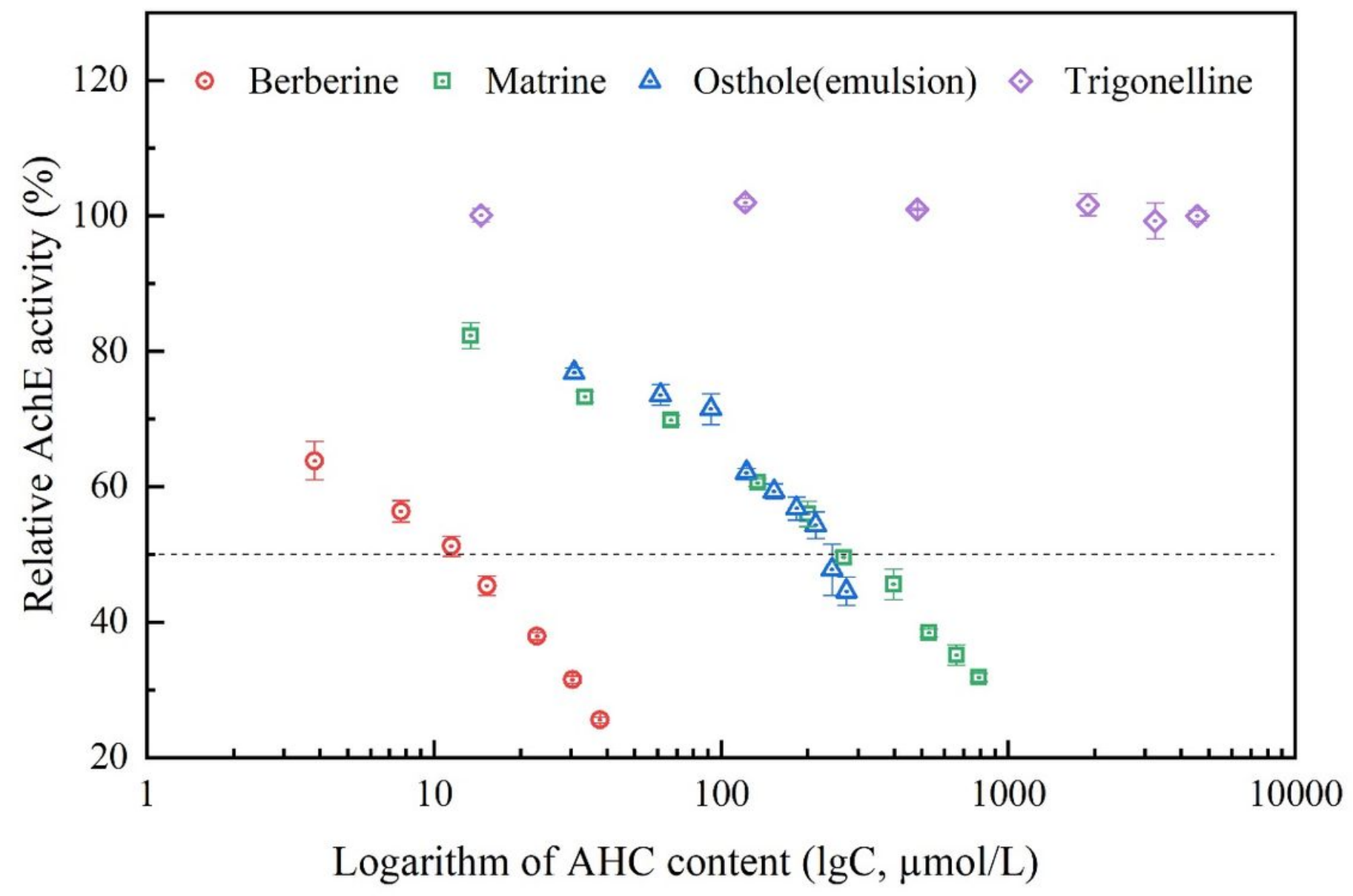

Figure 1

Inhibition of AchE activity by different AHCs at varied concentrations

Note: The test without addition of any AHC was set as reference (100\%)

Figure 2

Binding of acetylcholine and AHCs in AchE

Note: green - acetylcholine, red - berberine, purple - matrine, cyan - osthole, blue - trigonelline 


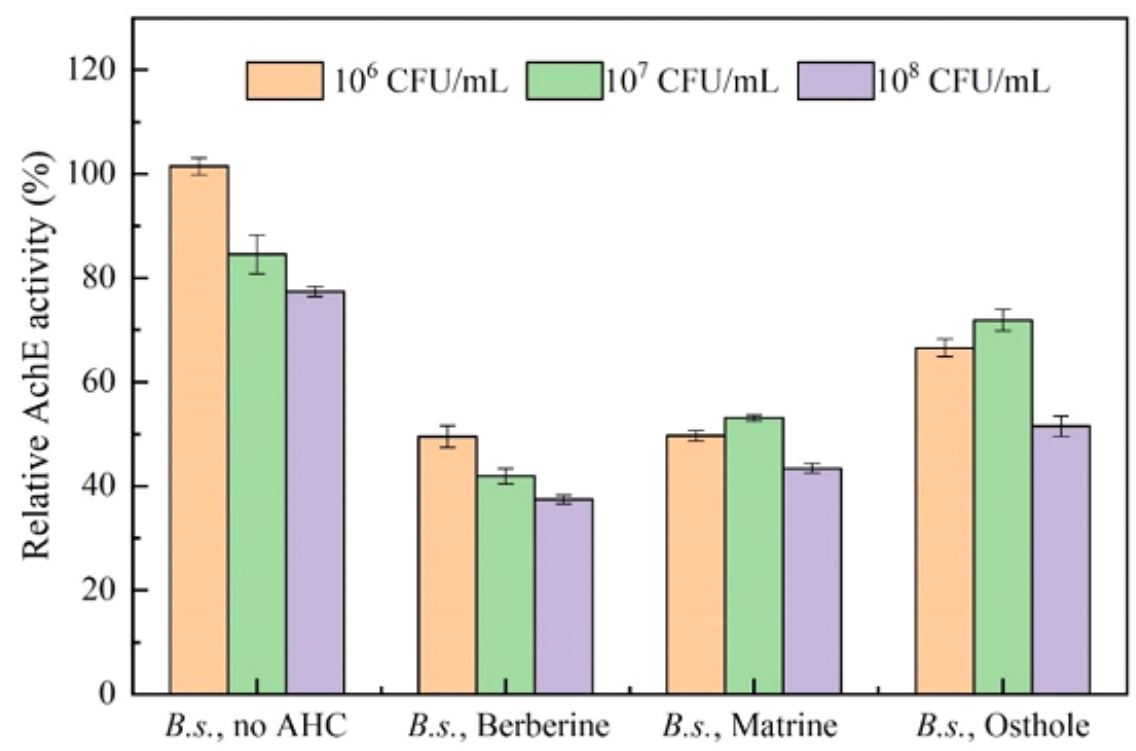

(a) B. stibilis Ruizhen ${ }^{\circledR}$.

Note: $\mathrm{IC}_{50}$ concentrations of $m$ atrine, berberine and osthole were used.

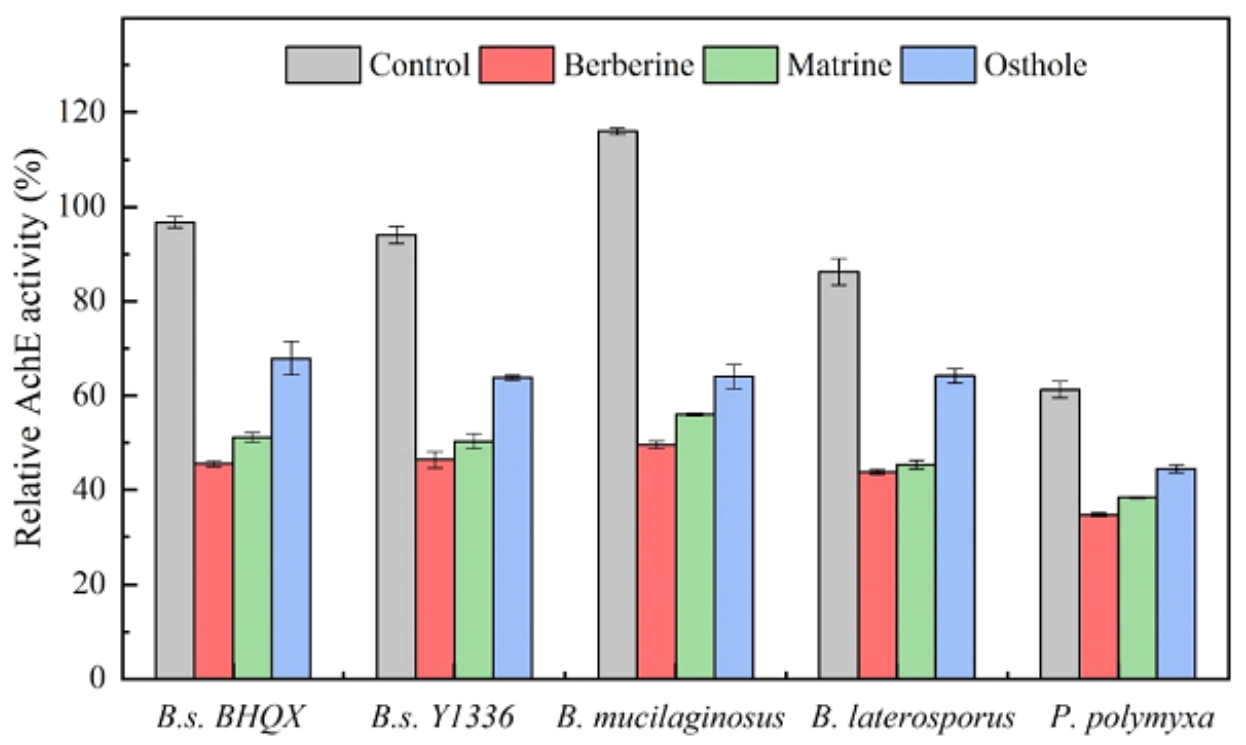

(b) Other Bacilli species

Note: $1 \times 10^{7} \mathrm{CFU} / \mathrm{ml}$ bacteria and $\mathrm{IC}_{5_{0}}$ concentrations of matrine, berberine and osthole were used

Figure 3

Effects of Bacillis on the AchE toxicity of AHCs 


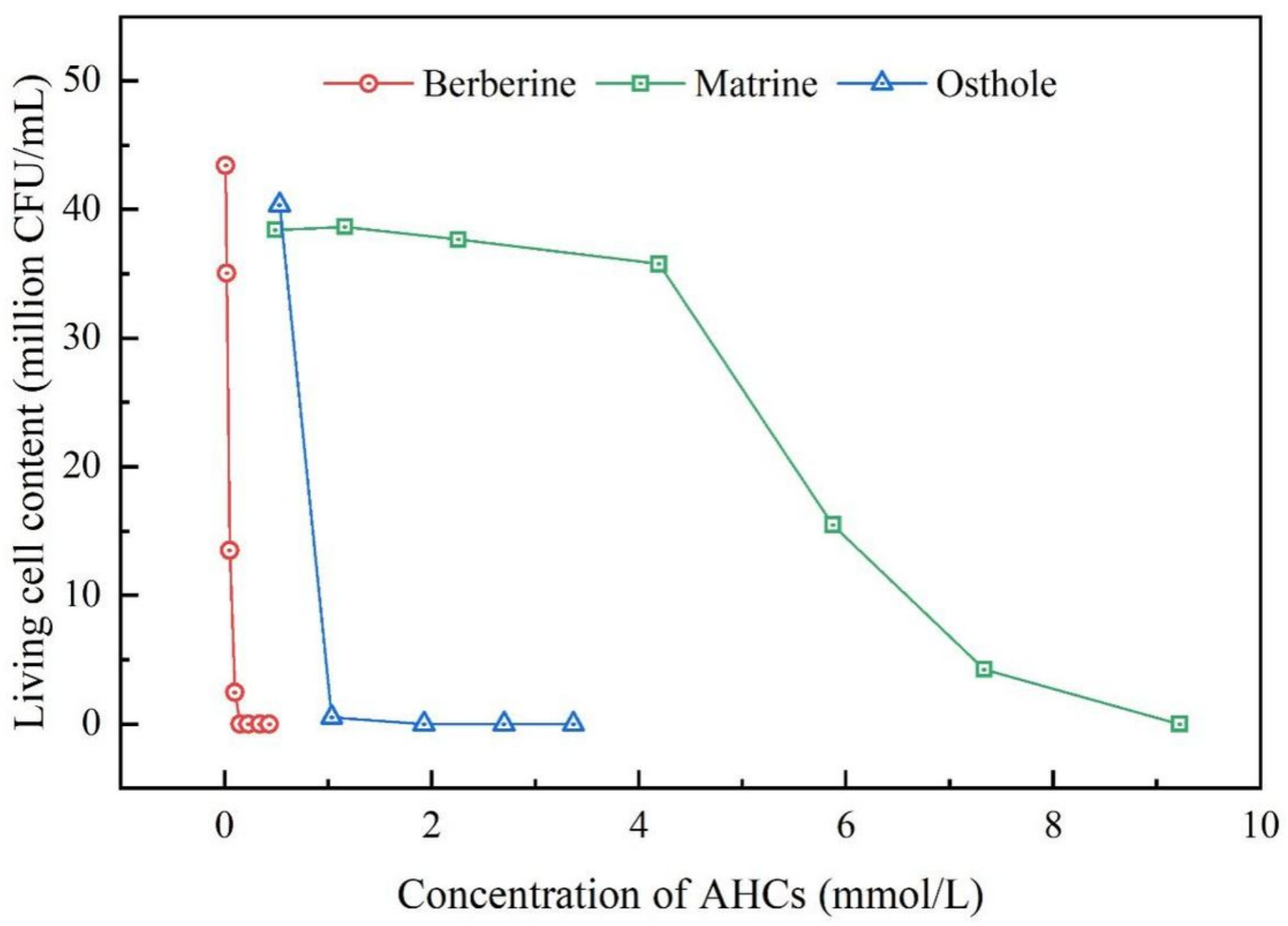

Figure 4

Inhibition of B. stibilis Ruizhen@ growth by AHCs

Note: Starting cell content $4.2 \times 10^{7} \mathrm{CFU} / \mathrm{g}$

Figure 5

Effects of the AHCs on the growth of B.subtilis Ruizhen

\section{Supplementary Files}

This is a list of supplementary files associated with this preprint. Click to download.

- Supplementaryfigure.docx 